\title{
$\mathrm{ARB}$ 공정에 따른 초미세립 AA1050/AA6061 복합알루미늄 합금 판재의 미세조직 발달 \\ 이성희 ${ }^{\dagger}$ \\ 국립목포대학교 신소재공학과
}

\section{Microstructural Evolution of Ultrafine Grained AA1050/AA6061 Complex Aluminum Alloy Sheet with ARB Process}

\author{
Seong-Hee Lee ${ }^{\dagger}$ \\ Department of Advanced Materials Science and Engineering, Mokpo National University, \\ Muan-gun, Chonnam 534-729, Korea \\ (2012년 11월 17일 접수 : 2012년 12월 6일 최종수정 : 2012년 12월 11일 채택)
}

\begin{abstract}
The microstructural evolution of AA1050/AA6061 complex aluminum alloy, which is fabricated using an accumulative roll-bonding (ARB) process, with the proceeding of ARB, was investigated by electron back scatter diffraction (EBSD) analysis. The specimen after one cycle exhibited a deformed structure in which the grains were elongated to the rolling direction for all regions in the thickness direction. With the proceeding of the ARB, the grain became finer; the average grain size of the as received material was $45 \mu \mathrm{m}$; however, it became $6.3 \mu \mathrm{m}$ after one cycle, $1.5 \mu \mathrm{m}$ after three cycles, and $0.95 \mu \mathrm{m}$ after five cycles. The deviation of the grain size distribution of the ARB processed specimens decreased with increasing number of ARB cycles. The volume fraction of the high angle grain boundary also increased with the number of ARB cycles; it was $43.7 \%$ after one cycle, $62.7 \%$ after three cycles, and $65.6 \%$ after five cycles. On the other hand, the texture development was different depending on the regions and the materials. A shear texture component $\{001\}<110>$ mainly developed in the surface region, while the rolling texture components $\{011\}<211>$ and $\{112\}<111>$ developed in the other regions. The difference of the texture between AA1050 and AA6061 was most obvious in the surface region; $\{001\}<110>$ component mainly developed in AA1050 and $\{111\}<110>$ component in AA6061.
\end{abstract}

Key words accumulative roll-bonding(ARB), electron back scatter diffraction(EBSD), complex aluminum alloy, ultrafine grain, texture.

\section{1. 서 론}

결정립초미세화를 위한 강소성가공법 중의 하나인 반 복겹침접합압연(Accumulative Roll Bonding, ARB)법은 다른 큰 장치 없이 종래의 압연기술을 활용할 수 있으 므로 판상의 대형 벌크재료에의 적용에 가장 적합한 프 로세스로 알려져 있다. ${ }^{1-10)}$ 일반적으로 $\mathrm{ARB}$ 법은 동일한 재료의 판재를 표면처리 후에 2매 적층하여 압하율 $50 \%$ 의 접합압연을 행하고, 길이를 2 등분하여 동일한 공정을
반복하는 방법으로 행해진다. 그러나 최근에는 종래의 $\mathrm{ARB}$ 법을 응용한 다층겹침 $\mathrm{ARB}$ 법, ${ }^{11)}$ 이종금속 $\mathrm{ARB}$ 법, ${ }^{12)}$ 동(同)종이(異)합금 $\mathrm{ARB}^{13,14)}$ 등에 대한 연구가 활 발히 진행되고 있다. 여기서 이종금속 $\mathrm{ARB}$ 법은 다른 종 류의 금속을 사용한 ARB법을 말하며, 이 방법은 초미 세결정립 조직을 가진 층상복합재료의 제조가 가능하며 그로 인해 다양한 특성을 발현시킬 수 있다는 장점이 있 다. 또한, 동(同)종이(異)합금 $\mathrm{ARB}$ 법이란 같은 금속이지 만 합금 종류가 다른 금속들을 $\mathrm{ARB}$ 법에 적용하여 다양

\footnotetext{
${ }^{\dagger}$ Corresponding author

E-Mail : shlee@mokpo.ac.kr (S. -H. Lee, Mokpo Nat'l Univ.)
}

(C) Materials Research Society of Korea, All rights reserved.

This is an Open-Access article distributed under the terms of the Creative Commons Attribution Non-Commercial License (http://creativecommons.org/licenses/by-nc/3.0) which permits unrestricted non-commercial use, distribution, and reproduction in any medium, provided theoriginal work is properly cited. 
한 조직과 기계적 특성을 가진 복합금속을 창제하는 방 법을 말한다. 본 연구그룹은 지난 연구들을 통해, AA1050 과 $\mathrm{AA} 5052$ 의 조합 $\left.{ }^{13,14}\right)$ 의 $\mathrm{ARB}$ 를 통해 다양한 조직의 층상복합알루미늄합금의 제조가 가능함을 보고한 바 있 다. 또한 어닐링을 통하여 더욱 다양한 복합조직과 기 계적 특성을 발현시킬 수 있음도 보고한 바 있다. ${ }^{14)}$ 그 런데 $\mathrm{ARB}$ 법은 압연을 기반으로 한 공정이므로 압연조 건에 따라 두께방향의 부위별 미세조직 및 집합조직의 형성이 동일하지 않다. 또한, 동종이합금 $\mathrm{ARB}$ 의 경우, $\mathrm{ARB}$ 에 따른 미세조직 및 집합조직의 형성과정이 기존 의 경우와 상이할 가능성이 크다. 따라서 본 연구에서 는 AA1050과 AA6061를 사용한 ARB공정에서, $\mathrm{ARB}$ 공 정에 따른 부위별 미세조직 및 집합조직의 발달과정을 Electron Back Scattering Diffraction(EBSD)측정을 통하 여 비교적 상세히 분석하였다.

\section{2. 실험 방법}

본 연구에서 $\mathrm{ARB}$ 공정을 위해 사용된 알루미늄합금 (출발재료)은 두께 $1 \mathrm{~mm}$, 폭 $30 \mathrm{~mm}$, 길이 $300 \mathrm{~mm}$ 의 AA 1050 의 순알루미늄과 두께 $2 \mathrm{~mm}$, 폭 $30 \mathrm{~mm}$, 길이 $300 \mathrm{~mm}$ 의 AA6061(Al-Mg-Si합금)판재이다. 두 알루미늄 합금의 화학조성을 Table 1에 나타내었다. 또한 두 합금 모두 $400{ }^{\circ} \mathrm{C}$ 에서 $0.5 \mathrm{~h}$ 어닐링된 상태이므로 재결정조직 을 나타내었으며 평균결정립경이 $\mathrm{AA} 1050$ 의 경우 $56 \mu \mathrm{m}$, $\mathrm{AA} 6061$ 의 경우 $34 \mu \mathrm{m}$ 이었다. $\mathrm{ARB}$ 는 두 재료를 겹쳐 냉간접합압연에 의해 두께를 $3 \mathrm{~mm}$ 에서 $2 \mathrm{~mm}$ 로 한 후 에 실시하였다. 즉 AA1050/AA6061의 clad재료를 ARB 공정에 사용하였다. Fig. 1에 ARB공정의 모식도를 나타 내었다. $\mathrm{ARB}$ 는 실온, 무윤활 조건에서 롤의 직경 $210 \mathrm{~mm}$ 의 압연기에 의해 롤의 주속 $15.9 \mathrm{~m} / \mathrm{s}$ 로 $5 \mathrm{c}(\mathrm{c}:$ cycle)까 지 행하였으며, 절단, 표면처리, 겹침, 접합압연 등의 일 련의 공정은 종래의 방법들 ${ }^{1-10}$ 과 동일하게 진행하였다.

$\mathrm{ARB}$ 후의 복합알루미늄 판재에 대하여 $\mathrm{EBSD}$ 측정을 통 한 미세조직 분석을 실시하였다. $\mathrm{EBSD}$ 측정의 경우, 판 재의 폭 중앙부에서 종단면(TD면)에 평행하게 압연방향 으로 시편을 얇게 잘라서, $30 \mathrm{vol} \% \mathrm{HNO}_{3}+70 \mathrm{vol} \% \mathrm{CH}_{3} \mathrm{OH}$ 용액속에서 액체온도 $-15^{\circ} \mathrm{C}$, 전압 $20 \mathrm{~V}$ 의 조건에서, twin jet 전해연마에 의해 경면으로 한 다음 $\mathrm{EBSD}$ 측정을 실 시하였다. 판재 두께 방향으로의 EBSD 측정은 Fig. 2 에 나타낸 것과 같이 $\mathrm{ARB}$ 시편의 판재 두께 중심부터

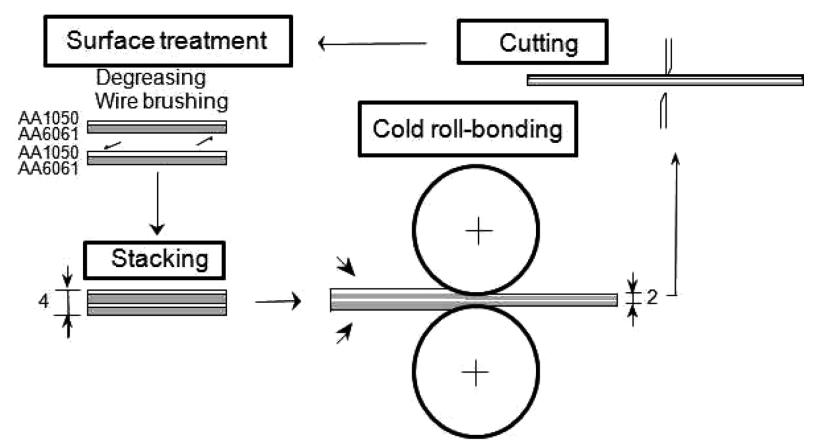

Fig. 1. Schematic illustration of accumulative roll bonding process using AA1050 and AA6061 alloys.

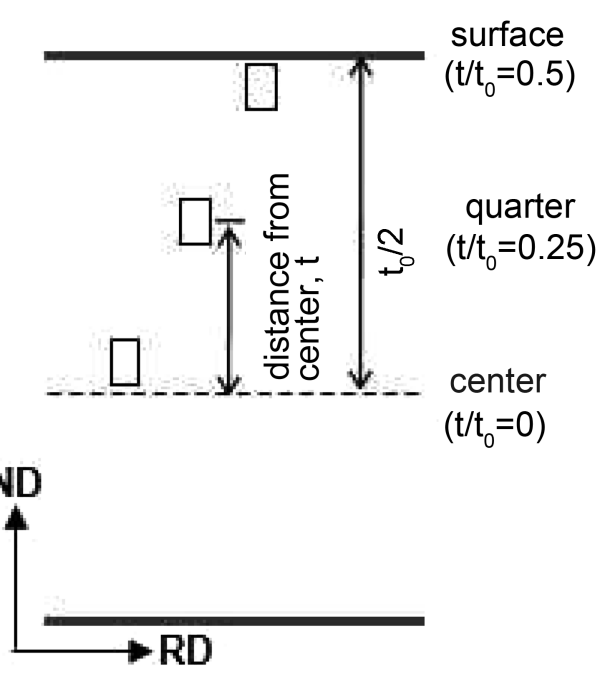

$\mathrm{t} / \mathrm{t}_{0}$ :normalized thickness location of the sheet

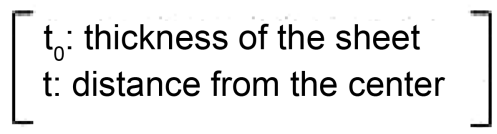

Fig. 2. Schematic illustration showing the measurement positions of electron back scatter diffraction for the ARB processed samples.

표면까지 여러 위치에 대해서 실시하였다. 이때 시편의 두께를 $\mathrm{t}_{0}$, 판재 두께 중심에서 측정영역 중심까지의 위 치를 $\mathrm{t}$ 로 하고, 각 측정영역의 판재 두께 위치를 규격 화 좌표 $\mathrm{t} / \mathrm{t}_{0}$ 를 사용하여 표현하기로 한다. 예를 들면, 판 재 두께 중심 및 표면위치는 각각, $\mathrm{t} / \mathrm{t}_{0}=0, \mathrm{t} / \mathrm{t}_{0}=0.5$ 라 고 표현된다. 측정된 $\mathrm{EBSD}$ 데이터로부터 $\mathrm{ND}$ 방위맵 (misorientation map), RD 방위맵 및 결정립계맵(grain boundary map)을 얻었다. ND 방위맵 및 $\mathrm{RD}$ 방위맵은 $\mathrm{EBSD}$ 측정에서 각 측정점의 압연면 법선방향(normal

Table 1. Chemical compositions of AA1050 and AA6061 studied (mass\%).

\begin{tabular}{ccccccccccc}
\hline Material & $\mathrm{Si}$ & $\mathrm{Fe}$ & $\mathrm{Cu}$ & $\mathrm{Mn}$ & $\mathrm{Mg}$ & $\mathrm{Cr}$ & $\mathrm{Zn}$ & $\mathrm{Ti}$ & Each & $\mathrm{Al}$ \\
\hline AA1050 & 0.03 & 0.29 & 0.02 & 0.01 & 0.01 & - & 0.01 & 0.009 & 0.03 & $\mathrm{RE}$ \\
$\mathrm{AA6061}$ & 0.6 & 0.7 & 0.3 & 0.15 & 1.0 & 0.155 & 0.25 & 0.15 & 0.05 & $\mathrm{RE}$ \\
\hline
\end{tabular}


direction; ND) 및 압연방향(rolling direction; RD)에 평행 한 결정방향을 표준 스테레오 삼각형으로 나타내었다. 여 기서 $\mathrm{EBSD}$ 측정에서 정확하게 검출할 수 있는 방위차 의 한계를 $2^{\circ}$ 라고 생각하고 방위차 $2^{\circ}$ 미만의 결정립계는 해석에서 제외했다. 즉, 본 $\mathrm{EBSD}$ 측정에서는 $2^{\circ} \sim 15^{\circ}$ 의 방위차를 가지는 결정립계를 저경각입계(low angle grain boundary), 방위차 $15^{\circ}$ 이상의 결정립계를 고경각입계(high angle grain boundary)라고 한다. 얻어진 EBSD 해석으 로부터 평균입경, 대각입계의 비율, 결정립계의 평균방위 차 각도 등의 미세조직 인자를 정량적으로 구하였다.

\section{3. 결과 및 고찰}

\subsection{1 cycle ARB재료}

Fig. 3 에 $1 \mathrm{c}-\mathrm{ARB}$ 재료의 표면부위 $\left(\mathrm{t}_{0} / \mathrm{t}=0.48\right)$, 중간부위 $\left(\mathrm{t}_{0} / \mathrm{t}=0.35\right)$, 센터부위 $\left.\mathrm{t}_{0} / \mathrm{t}=0\right)$ 의 $\mathrm{ND}$ map, $\mathrm{RD}$ map, $\mathrm{GB}$ $\mathrm{map}$ 을 나타내었다. 그림에서와 같이 부위에 관계없이 결 정립 크기가 유사하며 결정립이 압연방향으로 연신된 가 공조직을 나타냄을 알 수 있다. 그러나 집합조직에 있
어서는 부위에 따라 다소 다르다. AA1050의 표면부위 에서는 전단집합조직 성분의 하나(rotated cube)인 \{001\} $<110>$ 이 주로 발달한 집합조직을 나타내고 있다. 이것 은 압연시 압연롤과 시편사이의 마찰에 의해 표면부위 에 도입되는 전단변형에 기인한 것이라 판단된다. 그러나 중간부위의 경우, AA1050부위에서는 $\{011\}<211>$ (brass orientation)이, AA6061부위에서는 $\{112\}<111>$ (copper orientation)이 주로 발달하였다. 두 성분 모두 전형적인 압연 집합조직 성분이지만 재료에 따라 다른 집합조직을 나 타내는 것이 흥미롭다. 센터부위에서는 AA6061영역에서 는 $\{011\}<211>$ 성분이, AA1050영역에서는 $\{123\}<634>$ (S-orientation)성분이 발달하여 재료에 따라 다소 다른 집 합조직을 나타내었다. 또한 GB map을 통하여 misorientation이 $15^{\circ}$ 이상인 고경각입계가 $45.7 \%$ 인 반면, $15^{\circ}$ 이하 인 저경각입계가 $54.3 \%$ 임을 알 수 있었다. Fig. 4는 부 위별 결정립계의 misorientation angle의 체적분율을 나타 낸다. 표면부위와 중간부위는 분포도가 매우 유사하며 고 경각입계의 분율이 다소 높지만, 중앙부위에서는 저경각 입계의 분율이 다소 높은 경향을 나타내었다. Fig. 5 는
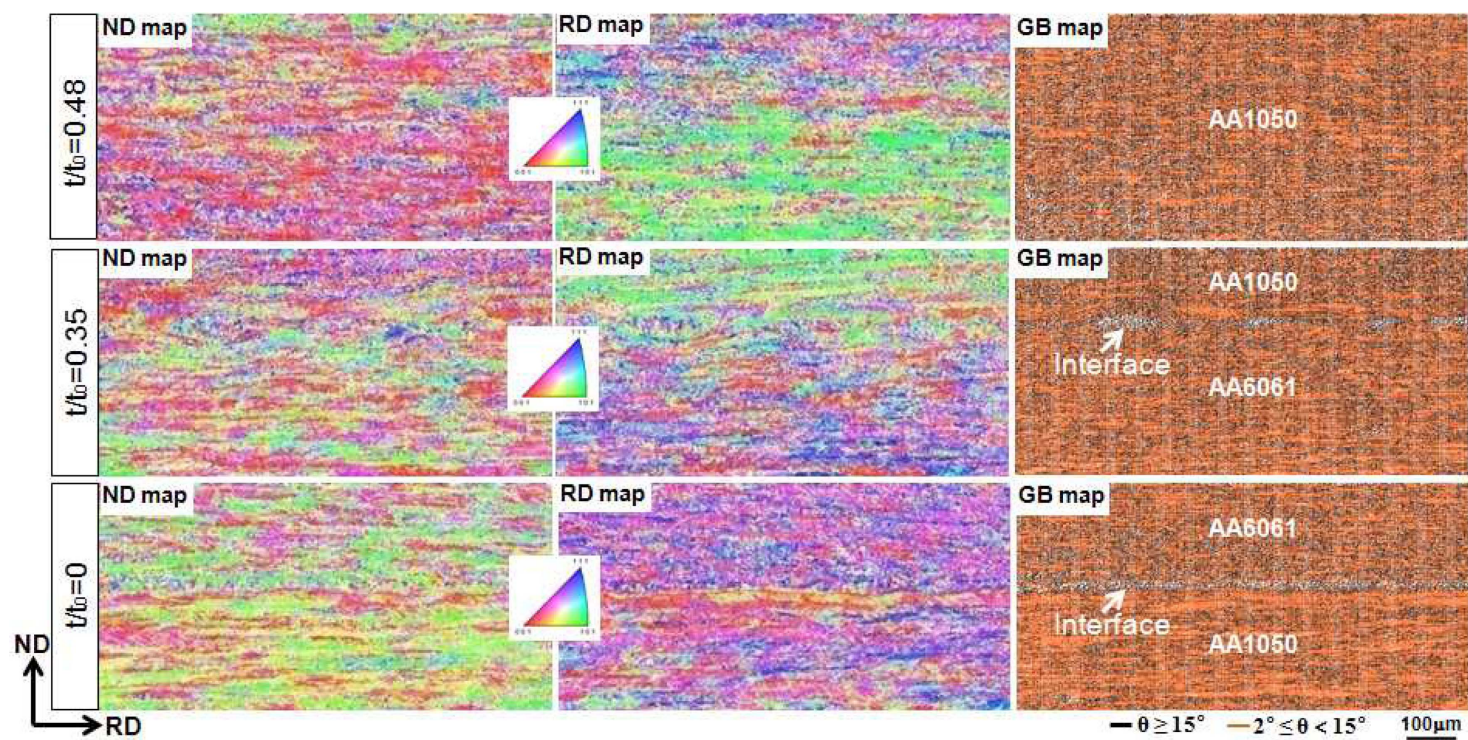

Fig. 3. ND maps, RD maps and GB maps obtained by EBSD measurement for the one cycle ARB processed sample.
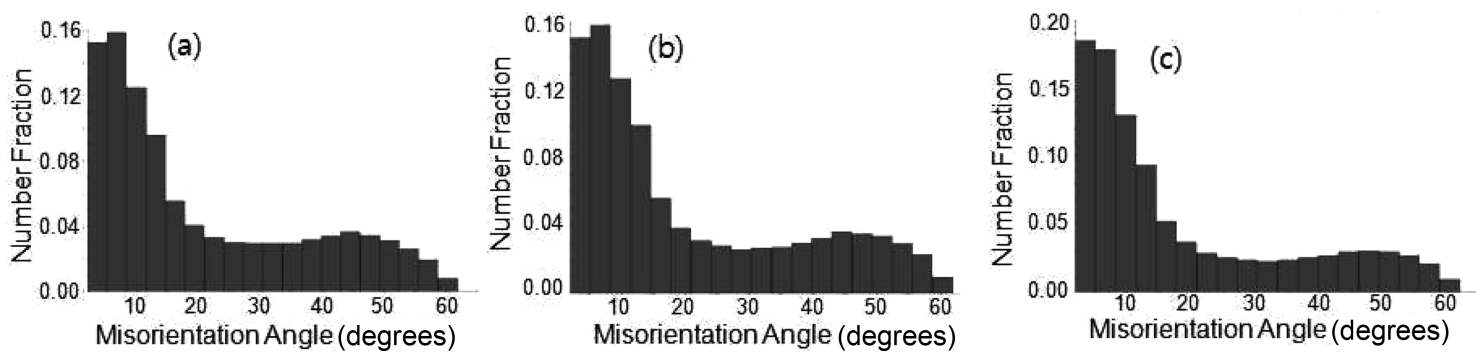

Fig. 4. Grain boundary misorientation angle distributions obtained by EBSD measurement for surface region $\left(t_{0} / t=0.48\right)(a)$, intermediate region $\left(\mathrm{t}_{0} / \mathrm{t}=0.35\right)(b)$ and center region $\left(\mathrm{t}_{0} / \mathrm{t}=0\right)(\mathrm{c})$ of the sample after one cycle. 

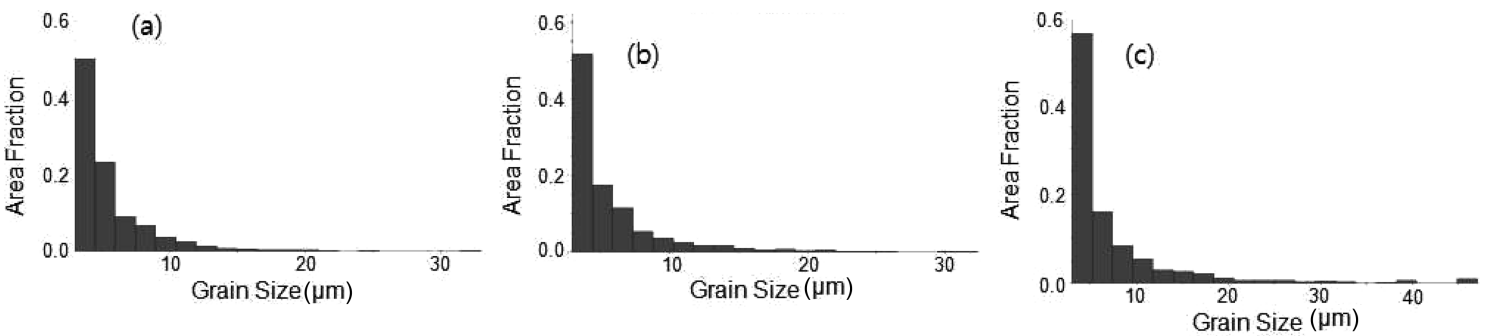

Fig. 5. Grain size distributions obtained by EBSD measurement for surface region $\left(t_{0} / t=0.48\right)(a)$, intermediate region $\left(t_{0} / t=0.35\right)(b)$ and center region $\left(\mathrm{t}_{0} / \mathrm{t}=0\right)(\mathrm{c})$ of the sample after one cycle.

부위별 결정립크기 분포를 나타낸 것이다. 어떤 부위에 서도 미세한(fine) 결정립의 체적분율이 증가하는 경향을 나타내고 있으며, 평균결정립 크기는 표면부위와 중간부 위에서는 각각 $5.5 \mu \mathrm{m}, 5.8 \mu \mathrm{m}$ 로 비슷하였으나 중심부위 에서는 $7.5 \mu \mathrm{m}$ 으로 다소 큰 경향을 나타내었다.

\subsection{3 cycle ARB재료}

Fig. 6 에 3c-ARB재료의 표면부위 $\left(\mathrm{t}_{0} / \mathrm{t}=0.48\right)$, 중간부위 $\left(\mathrm{t}_{0} / \mathrm{t}=0.35\right)$, 센터부위 $\left.\mathrm{t}_{0} / \mathrm{t}=0\right)$ 의 ND map, RD map, GB map을 나타내었다. 그림에서와 같이 부위에 관계없이 $1 \mathrm{c}-$ ARB재료(Fig. 3)에 비해 더 미세한 결정립을 나타내고 있으며 여전히 압연방향으로 연신된 가공조직을 나타낸 다. 그러나 집합조직에 있어서는 부위에 따라 다소 다 르다. 표면의 $\mathrm{AA} 1050$ 부위에서는 전단집합조직 성분의 하 나(rotated cube)인 $\{001\}<110>$ 이, AA6061의 경우에는 $\{111\}<110>$ 성분이 주로 발달한 집합조직을 나타내고 있 다. 그러나 중간부위 의 경우, AA6061부위에서는 $\{001\}$ $<110>$, AA1050부위에서는 copper orientation인 $\{112\}$

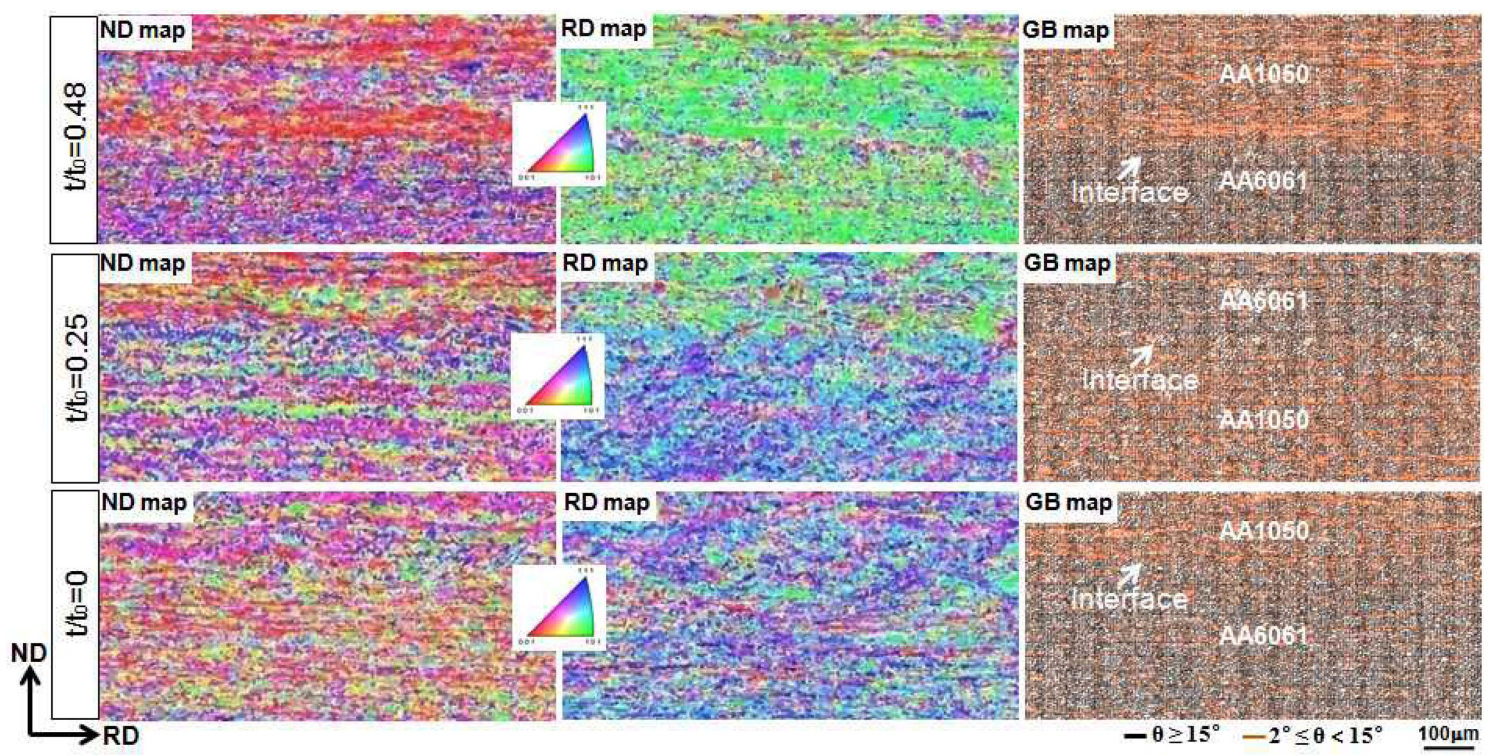

Fig. 6. ND maps, RD maps and GB maps obtained by EBSD measurement for the three cycle ARB processed material.
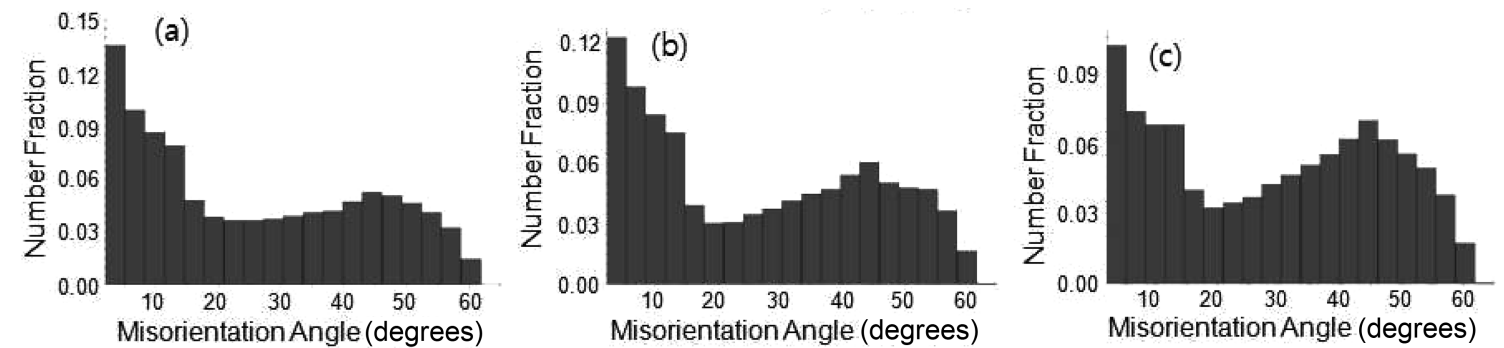

Fig. 7. Grain boundary misorientation angle distributions obtained by EBSD measurement for surface region $\left(t_{0} / t=0.48\right)(a)$, intermediate region $\left(\mathrm{t}_{0} / \mathrm{t}=0.35\right)(\mathrm{b})$ and center region $\left(\mathrm{t}_{0} / \mathrm{t}=0\right)(\mathrm{c})$ of the sample after three cycles. 

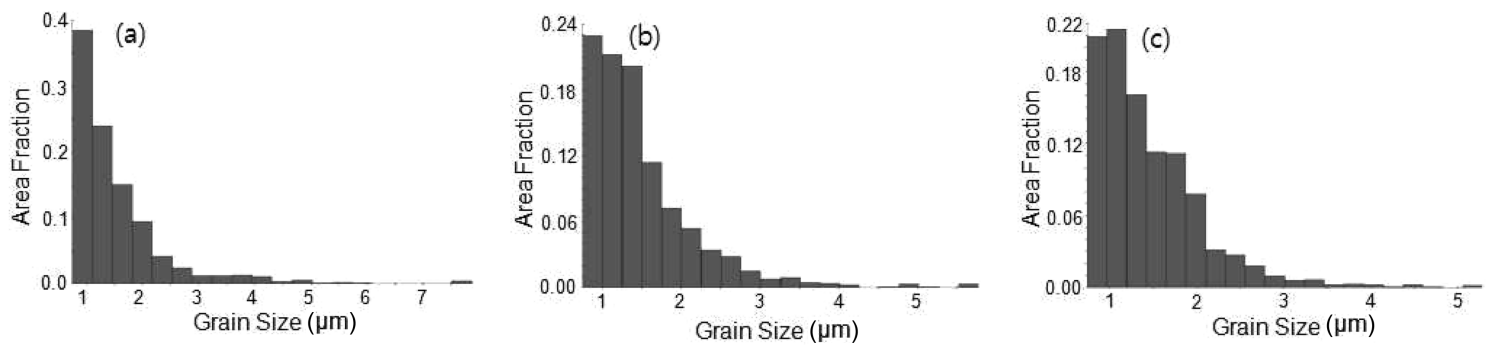

Fig. 8. Grain size distributions obtained by EBSD measurement for surface region $\left(t_{0} / t=0.48\right)(a)$, intermediate region $\left(t_{0} / t=0.35\right)(b)$ and center region $\left(\mathrm{t}_{0} / \mathrm{t}=0\right)(\mathrm{c})$ of the sample after three cycles.

$<111>0$ 이 주로 발달하였다. 센터부위에서는 그림에서와 같 이 모든 영역에서 $\{112\}<111>$ 성분이 발달한 집합조직을 나타내었다. Fig. 7에 부위별 misorientation angle의 체 적분율을 나타내었다. 표면부위와 중간부위는 분포도가 매 우 유사하며 고경각입계의 분율이 약 $60 \%$ 였으며, 중앙 부위에서는 $68 \%$ 로 다른 부위에 비해 고경각입계 비율 이 높은 경향을 나타내었다. 이것은 $1 \mathrm{c}-\mathrm{ARB}$ 재료와 다른 결과인데, 그 이유는 $1 \mathrm{c}$ 와 $2 \mathrm{c}$ 의 $\mathrm{ARB}$ 시에 표면부위에 형 성된 고경각입계 결정립들이 $3 \mathrm{c}$ 의 $\mathrm{ARB}$ 시에 중앙부위로 위치하기 때문인 것으로 해석된다. Fig. 8에 부위별 결 정립크기 분포를 나타내었다. 1c-ARB재료와 마찬가지로 어떤 부위에서도 미세한 결정립의 체적분율이 높은 경향 을 나타내었으나, 평균결정립 크기는 부위별로 큰 차이가 존재하지 않았으며 약 $1.5 \mu \mathrm{m}$ 이었다. 즉. $1 \mathrm{c}-\mathrm{ARB}$ 재료에 비해 두께방향으로 균질한 미세조직을 나타내었다.

\subsection{5 cycle ARB재료}

Fig. 9 에 $5 \mathrm{c}-\mathrm{ARB}$ 재료의 표면부위 $\left(\mathrm{t}_{0} / \mathrm{t}=0.48\right)$, 중간부위 $\left(\mathrm{t}_{0} / \mathrm{t}=0.35\right)$, 센터부위 $\left.\mathrm{t}_{0} / \mathrm{t}=0\right)$ 의 ND map, RD map, GB $\operatorname{map}$ 을 나타내었다. 그림에서와 같이 부위에 관계없이 $1 \mathrm{c}$ 과 $3 \mathrm{c}$ 의 $\mathrm{ARB}$ 재료에 비해 결정립이 더욱 미세화되고 aspect ratio가 작아져 등축(equiaxed)에 근접해 있음을 알 수 있다. 또한, 집합조직의 발달에 있어서도 부위별로 다 소 차이를 나타내었다. 표면의 $\mathrm{AA} 1050$ 부위에서는 전단 집합조직 성분의 하나인 $\{001\}<110>0$ 이, AA6061의 경우 에서는 $\{111\}<110>$ 성분이 주로 발달한 집합조직을 나타 내었다. 그러나 중간부위 및 센터부위의 경우, AA1050 에서는 $\{011\}<211>$, AA6061에서는 $\{112\}<111>$ 등 압연 집합조직이 주로 발달하였다. Fig. 10에 부위별 misorientation angle의 체적분율을 나타내었다. 그림에서와 같이 모든 부위의 분포도가 매우 유사하며 고경각입계의 분 율이 약 $65 \%$ 였다. 이것은 동종이합금의 $\mathrm{ARB}$ 에 있어서 도 $\mathrm{ARB}$ 사이클 수가 증가할수록 misorientation angle의 균일화가 촉진된다는 것을 잘 보여주는 결과라 할 수 있 다. Fig. 11에 부위별 결정립크기 분포를 나타내었다. 그 림에서와 같이 부위별로 결정립경 분포에 다소 차이가 있으나 평균결정립 크기는 약 $0.95 \mu \mathrm{m}$ 으로 거의 차이가 없었다. 이것 역시 $\mathrm{ARB}$ 싸이클 수가 증가할수록 미세조

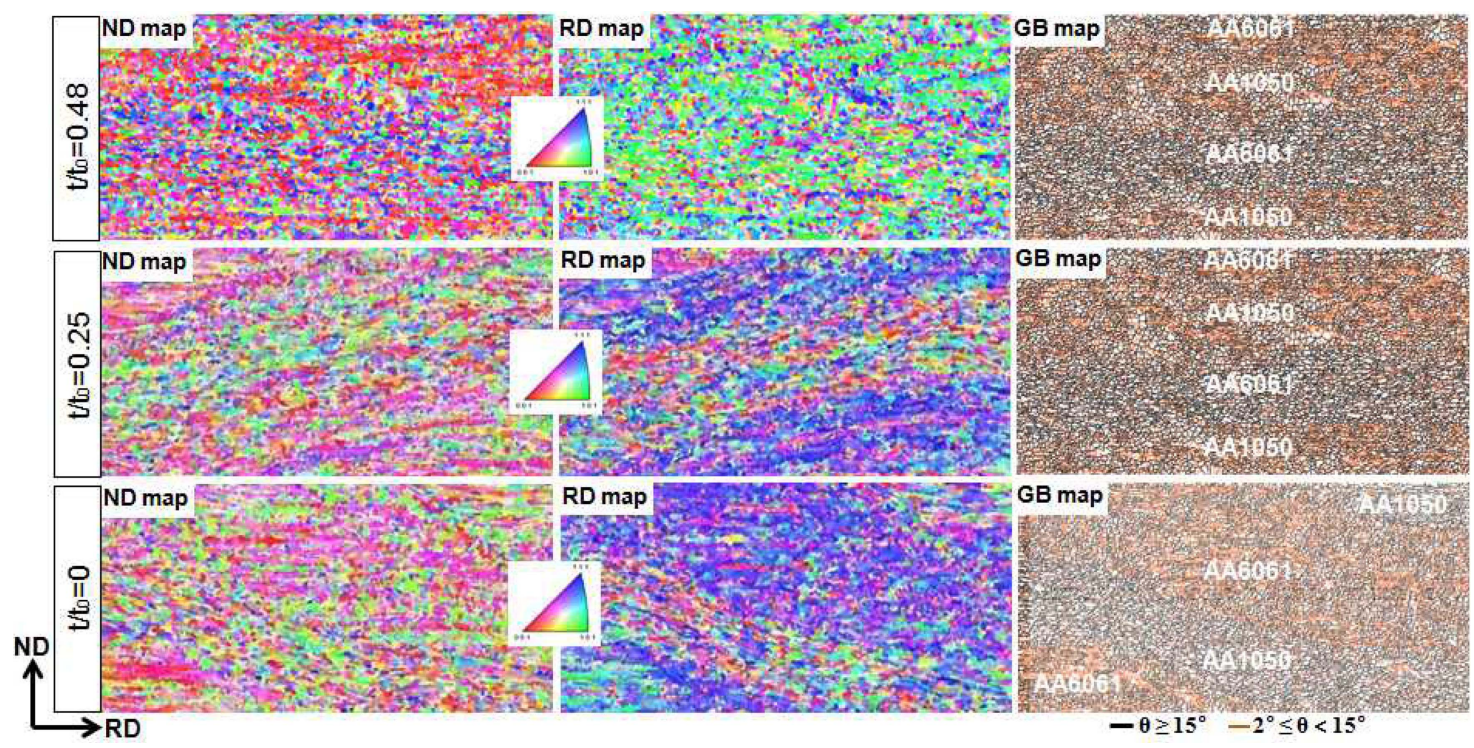

Fig. 9. ND maps, RD maps and GB maps obtained by EBSD measurement for the five cycle ARB processed material. 

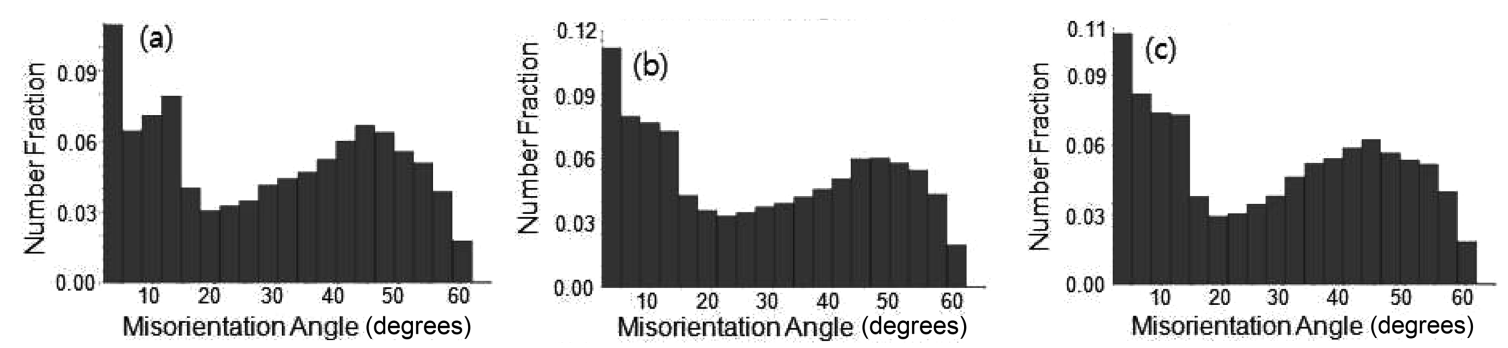

Fig. 10. Grain boundary misorientation angle distributions obtained by EBSD measurement for surface region $\left(t_{0} / t=0.48\right)(a)$, intermediate region $\left(\mathrm{t}_{0} / \mathrm{t}=0.35\right)(\mathrm{b})$ and center region $\left(\mathrm{t}_{0} / \mathrm{t}=0\right)(\mathrm{c})$ of the sample after five cycles.
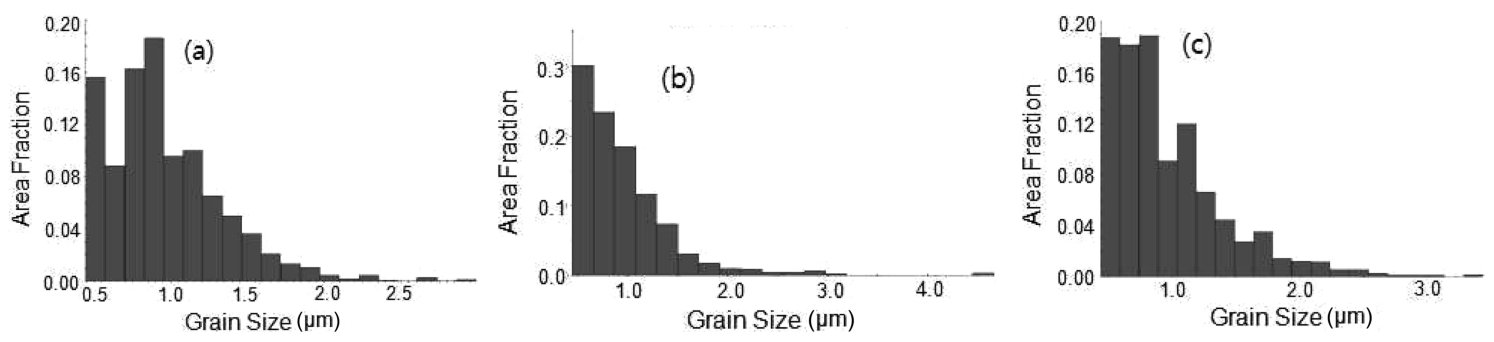

Fig. 11. Grain size distributions obtained by EBSD measurement for surface region $\left(\mathrm{t}_{0} / \mathrm{t}=0.48\right)(\mathrm{a})$, intermediate region $\left(\mathrm{t}_{0} / \mathrm{t}=0.35\right)(\mathrm{b})$ and center region $\left(\mathrm{t}_{0} / \mathrm{t}=0\right)$ ) (c) of the sample after five cycles.

직의 균일화가 촉진된 결과라 할 수 있다.

\section{4. 결 론}

$\mathrm{ARB}$ 법에 따른 $\mathrm{AA} 1050 / \mathrm{AA} 6061$ 층상복합알루미늄합금 의 미세조직 변화를 조사한 결과 다음과 같이 요약할 수 있다. 첫째, $\mathrm{ARB}$ 싸이클 수가 증가함에 따라 두께방향의 미세조직의 불균일성이 사라지고 비교적 균일한 조직을 형성하는 경향이 있다. 둘째, $\mathrm{ARB}$ 싸이클 수가 증가함에 따라 결정립미세화가 촉진되어 초기재료의 평균입경이 $45 \mu \mathrm{m}$ 이었던 것이 $1 \mathrm{c}$ 후에 $6.3 \mu \mathrm{m}, 3 \mathrm{c}$ 후에 $1.5 \mu \mathrm{m}, 5 \mathrm{c}$ 후 에는 $0.95 \mu \mathrm{m}$ 이 되었다. 셋째, 집합조직은 $\mathrm{ARB}$ 싸이클 수 에 따라 다소 차이는 있으나 표면부위는 전단집합조직, 중 앙부위와 센터부위는 압연집합조직이 주로 발달하였다. 다 만, AA1050, AA6061 별로 다소 다른 성분의 집합조직 이 발달하였다. 넷째, 결정립계의 방위차 각도가 $15^{\circ}$ 이 상인 고경각입계의 체적분율은 $1 \mathrm{c}$ 후에 $43.7 \%, 3 \mathrm{c}$ 후에 $62.7 \%, 5 \mathrm{c}$ 후에 $65.6 \%$ 로 점진적으로 증가하였다.

\section{감사의 글}

본 연구는 교육과학기술부와 전남과학기술진흥센터에 서 지원하는 "전남 과학연구단지 기초·원천연구개발지원 사업”에 의해 이루어졌으며, 관계자 여러분께 깊은 감사 를 드립니다.

\section{참 고 문 헌}

1. Y. Saito, N. Tsuji, H. Utsunomiya, T. Sakai and R. G. Hong, Scr. Mater., 39, 1221 (1998).

2. Y. Saito, H. Utsunomiya, N. Tsuji and T. Sakai, Acta Mater., 47, 579 (1999).

3. H. -W. Kim, S. -H. Jin and S. -B. Kang, J. Kor. Inst. Met. \& Mater., 39, 546 (2001) (in Korean).

4. S. H. Lee, Y. Saito, N. Tsuji, H. Utsunomiya and T. Sakai, Scr. Mater., 46, 281 (2002).

5. S. H. Lee, Y. Saito, T. Sakai and H. Utsunomiya, Mater. Sci. Eng. A, 325, 228 (2002).

6. S. H. Lee, J. Cho, S. Z. Han and C. Y. Lim, Kor. J. Mater. Res., 15(4), 240 (2005) (in Korean).

7. S. H. Lee, J. Cho, C. H. Lee, S. Z. Han and C. Y. Lim, Kor. J. Mater. Res., 15(9), 555 (2005) (in Korean).

8. S. H. Lee, S. Z. Han and C. Y. Lim, Kor. J. Mater. Res., 16(9), 592 (2006) (in Korean).

9. C. Y. Lim, S. Z. Han and S. H. Lee, Met. Mater. Int., 12(3), 225 (2006).

10. N. Takata, S. H. Lee and N. Tsuji, Mater. Lett., 63, 1757 (2009).

11. S. H. Lee, J. Kor. Inst. Met. \& Mater., 43, 786 (2005) (in Korean).

12. M. Eizadjou, A. K. Talachi, H. D. Manesh, H. S. Shahabi and K. Janghorban, Compos. Sci. Tech., 68, 2003 (2008).

13. S. H. Lee and C. S. Kang, Kor. J. Met. Mater., 49(11), 893 (2011) (in Korean).

14. S. H. Lee and G. J. Lee, Kor. J. Mater. Res., 21(12), 655 (2011) (in Korean). 